\title{
Eexiscapr.
}

BY WM. M. LESZYNSKY, M.D.

THE RESISTANCE OF THE HUMAN BODY IN ITS RELATION TO THE FARADIC CURRENT.

In the "Deutsch. Archiv. f. Klin. Med." Bd. xlv., Hft., 304, L. Mann has undertaken the study of a question in electrodiagnosis, which, up to this time, has not been explained. That is: In what measure is the intensity of an induced current flowing through the human body influenced by the resistance of the latter? As it appeared in the course of his experiments that metallic or fluid rheostats weakened in a very high degree the faradic current, and thus greatly changed the result of the faradic examination, the author substituted body-resistance in place of metallic resistance. The experiments were arranged according to the three following methods :

I. The resistance was increased by the introduction of a second person in the circuit.

2. The resistance was modified by changing the size of the electrodes.

3. The resistance was diminished by the action of the constant current, and by various chemical agents applied to the skin.

The results of these experiments may be thus summarized: That the body-resistance exercises a much smaller influence upon the intensity of the faradic current than upon that of the galvanic; therefore the resistance during the faradic examination may be neglected. In order to explain this fact, another experiment was made.

Starting from the establislied principle that the epidermis forms the main resistance to the galvanic current, a dead body was utilized in place of the living second person mentioned in the first series of experiments. The skin was then removed at the points of contact with the electrodes, and the behavior of the body-resistance to both currents tested with intact and removed epidermis. The result was that the resistance of the skinned body affected in the same degree the intensity of the faradic as that of the galvanic current. As in the intact skin the body-resistance affects the faradic current so mucl less than the galvanic, the conclusion is that this differing behavior has its cause in the epidermis; or, in other words, that the same possesses no influence over the induction current. 
As the neglect of the body-resistance to the induction current represents only an insignificant source of error, it follows that the simple measurement of the distance between the coils, without considering the resistance to conduction, perfectly suffices, for all practical purposes, for forming an estimate of the faradic irritability.

\section{THE EXPERIMENTAL STUDY OF REFLEX PUPILLARY IMMOBILITY.}

F. Mendel ("Deutsch. med.Wochenschrift," I 889, No.47,) reports that in a number of dogs, cats and rabbits, shortly after birth, as soon as the eyes were open, the iris was in greater part removed by means of a single or repeated iridectomy. The majority of the eyes operated upon were destroyed through suppuration of the globe.

After several months the animals were killed, and the brains examined by a series of sections.

Atrophy of the anterior corpora quadrigemina and the corp. geniculat. ext., on the opposite side, and atrophy of the ganglion habenula on the side of the operation, was found in those cases with suppuration of the globe and optic atrophy.

As a rule, in those cases where the eyeball was preserved, atrophy of the ganglion habenula appeared upon the side of the operation.

The assumption, therefore, seems warranted, that in the ganglion liabenula we have a centre for pupillary movement, whose development is arrested when it has no function to perform, as is seen in the case of iridectomized animals where no iris movement takes place. Darkschewitch has shown by means of anatomical and physiological studies, that the pupillary fibres of the optic tract enter in to the pineal gland and into the ganglion habenula.

In consequence of this, the ganglion habenula would have to be looked upon as the reflex centre for pupillary movement.

Gudden's statement as to a prominence situated in front of the superior corpora quadrigemina; also the physiological researches of Bechterew, Hensen, Völkers and Christiani, all of whom emphasize the importance of the third ventricle, especially its posterior wall, in its relation to pupillary movement, can easily be reconciled with the results of Mendel's investigations.

What, then, is the course of the reflex arc? 